\title{
Entre la modernidad y la tradición: la idea de filología en España en el siglo XVIII
}

Between modernity and tradition: approach to the idea of philology in Spain in the 18th century

Miguel Á. Perdomo-Batista

Universidad de Las Palmas de Gran Canaria

CESXVIII, núm. 30 (2020), págs. 469-483

DOI: https://doi.org/10.17811/cesxviii.30.2020.469-483

ISSN: 1131-9879

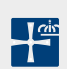




\section{RESUMEN}

Una aproximación a la idea de filología en España en el siglo XVIII revelará que, durante la centuria, no hubo una, sino varias filologías: la filología humanista de tradición clásica, la historia erudita (o erudición histórica) de filiación barroca, la erudición crítica de los novatores, la de influjo racionalista y la de influjo empirista, que alcanzó su cima en la obra de Juan Andrés. Nos proponemos mostrar cómo las nuevas tendencias conviven y se entremezclan con otra no menos importante: la tradición. Y en este sentido, es preciso señalar que durante esta centuria se produce el deslinde definitivo entre Historia y Filología, y que esta última se repliega sobre sí misma a partir de la consolidación de la Historia Literaria y la Historia Literaria Comparada. Finalmente, reflexionaremos sobre el estatuto de la Filología en relación con el propio movimiento ilustrado, es decir, respecto a su contribución u oposición a las nuevas ideas.

\section{Palabras clave}

Filología, historia, España, siglo XVIII, Juan Andrés.

\section{AbSTRACT}

An approach to the idea of philology in Spain in the 18th century will reveal that, during the century, there was not one, but several philologies: the humanist philology of classical tradition, the erudite history (or historical erudition) of baroque affiliation, the critical erudition of the novatores, that of rationalist influence and that of empiricist influence, which reached its peak in the work of Juan Andrés. We propose to show how the new tendencies coexist and intermingle with another no less important one: tradition. And in this sense, it is necessary to point out that during this century there is the definitive demarcation between History and Philology, and that the latter withdraws into itself from the consolidation of Literary History and Comparative Literary History. Finally, we will reflect on the status of Philology in relation to the Enlightenment movement itself, that is, in relation to its contribution or opposition to new ideas.

KeY WoRDS

Philology, History, Spain, $18^{\text {th }}$ century, Juan Andrés.

Recibido: 16 de enero de 2020. Aceptado: 18 de marzo de 2020. 


\section{Introducción}

Cuando se trata de mostrar la historia de las ideas lingüísticas en el siglo XVIII, a menudo se hace asignando las obras o el pensamiento examinado a las corrientes racionalistas o empiristas, con lo cual se hace historia de las ideas (lo cual no está nada mal) pero no necesariamente historiografía de la linguiística. La mera reconstrucción racional de los hechos no siempre conduce a un discurso histórico, porque una cosa es «lo que debió ocurrir» y otra bien distinta "lo que en efecto ocurrió», si es que de verdad nos es dado penetrar en el pasado. Xavier Laborda ${ }^{1}$, por ejemplo, en su tesis doctoral sobre la influencia de Port Royal y del pensamiento empirista en las ideas lingüísticas del siglo XVII, mostró que el intento de caracterizar las obras por su influjo racionalista o empirista era insuficiente, porque ambas tendencias se concitaban en las obras, y ambas coexistían con otra no menos importante: la tradición. Y este es precisamente el punto de vista que me propongo adoptar en mi examen de la Filología española del siglo XVIII. En el mundo académico, vivimos inmersos en el «mantra» de la «innovación», derivación reciente de dos categorías de la modernidad, las de «progreso» y «cambio». Lo llamo «mantra» porque la idea se repite constantemente sin la debida atención. Porque, ¿cómo podría haber innovación sin tradición? ¿Cómo podrá haber cambio en lo inconstante? Gadamer ${ }^{2}$ nos señaló hace tiempo que, desde el punto de vista hermenéutico, la tradición (incluidos los prejuicios) es necesaria para avanzar, porque nos proporciona las categorías con las que podemos comprender. Su crítica de la Ilustración es una crítica contra el prejuicio ilustrado contra todo prejuicio, y con ello la desvirtuación de toda tradición. Debe advertirse que en absoluto estoy defendiendo el tradicionalismo, sino que censuro lo que me parece una forma de esnobismo intelectual, tanto más dañino cuanto que se reviste de progresismo.

1 Xavier Laborda GIL, Racionalismo y empirismo en la lingüística del siglo XVII: Port-Royal y Wilkins. Disponible en: https://www.tdx.cat/handle/10803/1727 [Consulta: 20/09/2019]. Es la tesis doctoral de su autor, defendida en la Universidad de Barcelona en 1981.

2 Hans-Georg Gadamer, Wahrheit und Methode. Grundzüge einer philosophischen Hermeneutik, Tübingen, 1969. vols. I-II [Verdad y método. Salamanca: Sígueme, 1997 [ [1960], vol. I, págs. 337-353. 
Adoptando esta perspectiva, me propongo mostrar las principales tendencias de la filología española del siglo XVIII: la de influjo racionalista, la de influencia empirista, la erudición crítica de los novatores, la historia erudita (o erudición histórica) de filiación barroca y renacentista y la tendencia humanista de tradición clásica. Se pondrá de manifiesto cómo las nuevas tendencias se incardinan en la tradición, a menudo al amparo de las instituciones de la Monarquía.

Finalmente, la dimensión institucional de alguna de las tendencias de la filología dieciochesca española nos mueve a preguntarnos por la contribución (u oposición) de la actividad filológica al pensamiento ilustrado, cuestión de la que se han ocupado Antonio Mestre Sanchis ${ }^{3}$ y Francisco Sánchez-Blanco ${ }^{4}$.

Así, pues, nuestro examen tiene dos vías: el contenido práctico de la actividad filológica (en relación con sus tendencias y objetivos), el estatuto de la misma Filología (en relación con otras disciplinas y con el propio pensamiento ilustrado). Comenzaremos por lo primero porque ayudará a objetivar el lenguaje y a no errar el camino. Para ello, empezaremos con un rápido análisis del propio término filología (o philologia, según la ortografía helenizante).

En cuento a los testimonios lexicográficos, el Nuevo Tesoro Lexicográfico de la Lengua Española de la RAE $^{5}$ documenta la voz philologia en el diccionario de Bluteau de $1721^{6}$ y en el Diccionario de Autoridades en $1737^{7}$. Nieto y Alvar ${ }^{8}$ también remiten a Bluteau. Corominas ${ }^{9}$ documenta filólogo y filología en 1732, y filológico en el siglo XVII.

Respecto a los testimonios propiamente lexicológicos, el primer testimonio de philología que hallamos en el Nuevo Diccionario Histórico de la Lengua Española de la $\mathrm{RAE}^{10}$ corresponde a Medidas del romano, obra de Diego de Sagredo publicada en $1526^{11}$. Y la fecha no es casual, pues justamente a mitad

3 Antonio Mestre Sanchís, Humanistas, políticos e ilustrados, Alicante, Universidad de Alicante, 2002.

4 Francisco Sánchez-Blanco, La mentalidad ilustrada, Madrid, Taurus, 1999.

5 Real Academia Española, Nuevo tesoro lexicográfico de la lengua española, Madrid, Real Academia Española y Espasa Calpe. Edición digital en un estuche con 2 DVD-ROM acompañados de un manual de instrucciones. Disponible en: http://ntlle.rae.es/ntlle/SrvltGUILoginNtlle [Consulta: 20/09/2019].

6 Rafael Bluteau, Diccionario castellano, y portuguez [...], Lisboa, Imprenta de Pascoal da Silva. 1721.

7 Real Academia Española, Diccionario de Autoridades, edición facsímil, Madrid, Gredos, 1990

[1726-1737]. Puede consultarse también la edición en línea: http://web.frl.es/DA.html.

8 Lidio Nieto y Manuel Alvar, Nuevo tesoro lexicográfico del español (S. XV-1726), Madrid, Arco libros, 2007, vol. v, pág. 4833.

9 Joan Corominas, Breve diccionario etimológico de la lengua castellana, Madrid, Gredos, 1973 [1961], pág. 273.

10 Real Academia Española, Nuevo diccionario histórico del español, Disponible en: http://web.frl.es/ CNDHE/view/inicioExterno.view [Consulta: 20/09/2019].

11 Diego de Sagredo, Medidas del romano, Toledo, [s. n.], 1526, fol. 2 v. 
del siglo XVI se está produciendo la transformación del humanismo en erudición, como veremos en el siguiente apartado.

\section{El Humanismo se transforma en erudición: Morales, Zurita y Agustín}

Y en efecto, en la segunda mitrad de siglo Xvi hay que situar la obra de tres eruditos humanistas de los cuales parten algunas de las líneas que tendrán continuidad en la filología dieciochesca: Ambrosio de Morales, Jerónimo Zurita y Antonio Agustín. Representan las tres líneas de trabajo dominantes en la erudición histórica, que tendrán continuidad en el siglo XVIII: los trabajos bibliográficos, el trabajo de archiveros y medievalistas y, finalmente, la erudición jurídica y la historia eclesiástica.

Morales, que estuvo vinculado a la Biblioteca de El Escorial, se interesó por la numismática, la epigrafía, la paleografía, la bibliografía y la filología clásica. Morales y Arias Montano, vinculado también a la biblioteca de El Escorial, representan los estudios eruditos orientados a la bibliografía en las bibliotecas del Estado. En este sentido, hay que recordar que realizó un viaje erudito por León, Galicia y Asturias por encargo de Felipe II. Como puede suponerse, la línea de los estudios bibliográficos está relacionada con la Bibliotheca hispana de Niolás Antonio y, ya en el siglo XVIII, con el catálogo de manuscritos griegos de Juan de Iriarte ${ }^{12}$, la Bibliotheca de Casiri ${ }^{13}$ y la reedición de Nicolás Antonio dirigida por Pérez Bayer ${ }^{14}$, uno de los principales proyectos editoriales de la Monarquía.

Zurita fue latinista (su modelo era Tácito) y trabajó en los archivos, actividad seguramente relacionada con su designación como Cronista de Aragón. Se

\footnotetext{
12 Juan de Iriarte, Regiae bibliothecae Matritensis codices graeci MSS [...], Matriti, e Typographia Antonii Pérez de Soto. Anno MDCCLXIX.

13 Miguel CASIRI, Bibliotheca arabico-hispana escurialensis [...], Madrid, Antonio Pérez de Soto, 1760.

14 Nicolás Antonio, Bibliotheca hispana nova sive hispanorum scriptorum qui ad anno MD ad MDCLXXXIV floruere noticia, auctore D. Nicolao Antonio [...], tomus primus [-secundus], Matriti, apud Joachim de Ibarra, 1783-1788 [1672]. [Biblioteca hispana nueva o de los escritores españoles que brillaron desde al año MD hasta el de MDCLXXXIV; autor, Nicolás Antonio. 2 vols. y 1 cederrón compartido con la Bibliohteca hispana vetus. Madrid, Fundación Universitaria Española, 1999. Es traducción de la edición hecha por Pérez Bayer entre 1783 y 1788].

Nicolás ANTONIO, Bibliotheca hispana vetus sive hispani scriptores qui ab Octaviani Augusti aevo ad anuum Christi MD floruerun, auctore D. Nicolao Antonio [...] curante Francisco Perezio Bayerio [...] tomus primus [-secundus], Matriti: apud viudam et heredes D. Ioachim Ibarrae, 1788 [1696] [Biblioteca Hispana Antigua o de los escritores españoles que brillaron desde Augusto hasta el año de Cristo de MD; autor, Nicolás Antonio; editor, Francisco Pérez Bayer, 2 vols. Madrid, Fundación Universitaria Española, 1998. Es traducción de la edición hecha por Pérez Bayer en 1788].
} 
ocupó de numismática, epigrafía, bibliografía, y textos jurídicos; y en él hallamos representada la línea de los archiveros y medievalistas que tendrá luego continuidad en los trabajos de Burriel, Sarmiento, Tomás Antonio Sánchez y algunos proyectos de la Real Academia de la Historia.

Agustín fue teólogo y canonista. Su contribución al nacimiento de la numismática como disciplina fue decisiva. Lo más destacable es su interpretación de las instituciones como fuentes del derecho. En Agustín hallamos la línea de la erudición jurídica y la historia eclesiástica que alcanza a Mayans y Flórez ${ }^{15}$.

Como se habrá observado en este sucinto repaso, desde la segunda mitad del siglo XVI, lo institucional (bibliotecas, archivos, puestos de cronistas) está condicionando la evolución de la erudición histórica. Algo semejante sucederá con la filología dieciochesca.

\section{La erudición hispana en el siglo XVII}

En siglo XVII, tres hechos caracterizan la erudición hispana y confluyen con las tendencias anteriores: la elaboración de repertorios bibliográficos, las actividades de los benedictinos de Valladolid y la historiografía de los novatores.

En cuanto a la elaboración de repertorios bibliográficos, es preciso destacar, por un lado, los trabajos de Tamayo de Vargas y Ramírez de Prado, y, por otro, los repertorios de las órdenes religiosas, de los que debemos recordar el Illustrium scriptorum de Ribadeneira ${ }^{16}$, que estableció el formato: una breve biografía seguida de la relación de obras. En otro ámbito, debemos recordar también el Epítome de León Pinelo ${ }^{17}$, continuado en el XVIII por González de la Barcia $^{18}$.

Respecto de los benedictinos de Valladolid, es necesario recordar sus contactos con los maurinos y su propósito de elaborar una crónica de la orden un siglo antes que Mabillon ${ }^{19}$, aunque, naturalmente, los esfuerzos de Antonio Yepes

15 Enrique Flórez [DE SETIÉN] y Manuel Risco. España sagrada: teatro geographico-historico de la iglesia de España [...], Madrid, Miguel Francisco Rodríguez, 1747-1918. Los volúmenes que van del 1 al 29 son de Flórez; del 30 al 43 son de Risco. La obra tuvo después varios continuadores que completaron los 54 volúmenes de que consta.

16 Pedro de Ribadeneyra, Illustrium scriptorum religionis Societatis Iesu catalogus, Antuerpiae, Officina Plantiniana, 1608.

17 Antonio de León Pinelo, Epitome de la biblioteca Oriental i Occidental, Nautica i Geografica [...]. Madrid, Iuan González, 1629.

18 Andrés González de la Barcia, Epítome [...], Madrid, Francisco Martínez Abad, 1737.

19 Antonio Mestre Sanchís, Apología y crítica en España en el siglo XVIII, Madrid, Marcial Pons, 2003, pág. 251. 
y Pérez Rozas perdieron mucha importancia tras las publicaciones de Mabillon. Los benedictinos son los continuadores de documentalistas y archiveros.

Finalmente, es preciso destacar la importancia de la historiografía de los novatores, representados por Sáenz de Aguirre, Juan Lucas Cortés, el Marqués de Mondéjar ${ }^{20}$ y Nicolás Antonio.

El cardenal Sáenz de Aguirre, autor de una colección de concilios ${ }^{21}$, requiere un comentario aparte, porque es el enlace entre la historia erudita de origen renacentista y barroco y la historiografía crítica de los novatores. Y en efecto, la única obra de autor español en cuyo título hemos hallado la palabra polimatía $^{22}$ (polymathia) es de Sáenz de Aguirre $(1668)^{23}$. Como se sabe, el polímata era una suerte de erudito con conocimientos universales, y quizá se trate de un lejano precedente del enciclopedista.

Los novatores fueron hombres de ciencia que se abrieron a las corrientes europeas. Muchos de ellos eran médicos de tendencia empirista de Sevilla, Madrid o Zaragoza. Conscientes del declive nacional (visible en la aceptación sin crítica de los falsos cronicones ${ }^{24}$ ) reivindican un pasado glorioso sin caer en un apologismo vacuo y acrítico. En tal contexto, la erudición, que era la base de la argumentación, tenía mucha importancia. Para ellos, la verdadera apología de España pasaba por la erudición unida a la crítica. Nicolás Antonio representa

20 Gaspar de Ibáñez de Segovia y peralta fue autor de una importantísima y dilatada obra, de la que citaremos al menos el Discurso histórico por el patronato de San Frvtos, Zaragoza: Juan de Ibar, 1666; Obras chronologicas de don Gaspar Ibáñez de Segovia [...], publicadas por Mayans en Valencia: Bordazar de Artazú, 1744; Advertencias a la historia del padre Juan de Mariana, publicadas también por Mayans en Valencia: Bordazar de Artazú, 1746.

21 José SÁenz de Aguirre, Collectio maxima conciliorum [...], Romae, typis Joannis Jacobi Komarek Bohemi apud S. Angelum custodem, 1693-1694, 4 vols. Hay edición española: Madrid, Ibarra, 1784.

22 Álavarez de Miranda dedica un oportuno apartado a esta voz en Palabras e ideas: el léxico de la Ilustración temprana en España (1680-1760). Anejo LI del Boletín de la Real Academia Española. Madrid: RAE, 1992. Afirma (490) que la voz se documenta ya en 1736; y añade (686) que fue un neologismo de vida efímera.

23 José SÁEnZ de Aguirre, Ludi salmanticenses seu Theologia florulenta [...], opus varium et polymathia plenum [...], Salmanticae, ex officina Melchioris Esteues, 1668.

${ }_{24}$ La expresión falsos cronicones comprende una serie de obras producidas por la erudición española del siglo XVI e interesada especialmente por la investigación del Santoral, según las corrientes pietistas de la época. El patriotismo local se enorgullecía de la antigüedad de sus poblaciones y del mayor número posible de santos. Los falsos cronicones defendían estas creencias surgidas de la devoción popular atribuyéndolas a autores antiguos cuya existencia tenía mayor o menor verosimilitud. La opinión de los eruditos sobre la credibilidad de los cronicones se dividió en la primera mitad del xvII, y puede decirse que hacia 1650 comúnmente se dudaba de su veracidad. Naturalmente los novatores y los ilustrados criticaron estas obras, consideradas como un producto de la devoción y la superstición, aunque muy pocos se atrevieron a manifestar abiertamente su oposición a algunas tradiciones muy arraigadas sobre los orígenes del cristianismo en España, como la venida de Santiago o los relatos sobre la Virgen del Pilar.

${ }^{46}$ Antuerpiae: apud Ioannem Moretum, 
muy bien ambas tendencias: la erudita, en su Bibliotheca hispana; la crítica, en su Censura de historias fabulosas ${ }^{25}$. Debe señalarse, no obstante, que la mayoría de los novatores no se pronunciaron sobre la autenticidad de los cronicones. Tampoco los hombres de la Ilustración, a excepción de Manuel Martí y Mayans, se atrevieron a exponer públicamente sus dudas.

Puede decirse que la Histoire littéraire de la France ${ }^{26}$ de los maurinos es un antecedente de la obra de Antonio, y que existe una línea que parte de la Histoire, pasa por Antonio y alcanza la obra de Juan Andrés. Puede afirmarse también que el desarrollo de la historia literaria española del siglo XVIII es fruto de la erudición crítica introducida por los novatores, que se cultiva hasta finales de siglo, cuando la erudición histórica ya parece superada.

Esa superación de la erudición histórica se advierte muy bien en el tratamiento satírico de la actividad filológica (representada por los gramáticos) que podemos hallar, por ejemplo, en La derrota de los pedantes, publicada por Moratín en $1789^{27}$. La obra es una sátira contra los malos poetas, a los que Moratín llama filólogos. Dirige sus dardos contra el prosaísmo poético, las malas traducciones, el teatro tradicional y la erudición superficial y pedante. Son tópicos de la época que encontramos también en las Exequias de Forner ${ }^{28}$, Los eruditos ${ }^{29}$ de Cadalso o Los literatos en Cuaresma ${ }^{30}$ de Iriarte.

A finales de siglo, la filología concebida como la unión de todas las clases de literatura parece estar superada, sobre todo si degenera en erudición pedante o superficial. Moratín percibe el exceso erudito como una pervivencia de la tradición barroca. Lo que resulta fácil de entender si recordamos que la historia erudita se consolida precisamente en el siglo XVII. Y eso fue la filología en gran medida durante el siglo XVII y aún durante la siguiente centuria hasta que se deslindó de la erudición y la historia y adoptó unos límites más definidos, como sucede en la propuesta de Juan Andrés. A lo que estamos asistiendo es a la su-

25 Fue reeditada por Gregorio MaYAns, «Censura de historias fabulosas», obra póstuma de don Nicolás Antonio [...] van añadidas algunas cartas del mismo autor y de otros eruditos; publica estas obras don Gregorio Mayans y Siscar, autor de la vida de don Nicolás Antonio. Valencia: Antonio Bordazar de Artazú, 1742 [en línea]. Biblioteca Virtual Miguel de Cervantes, Fundación Biblioteca Virtual Miguel de Cervantes, Universidad de Alicante. Disponible en: http://www.cervantesvirtual.com/ [Consulta: 20/09/2019].

26 Antoine Rivet de La Grange (dir.), Histoire littéraire de la France, París, 1733-1763, 12 vols. En 1814 el trabajo fue reanudado por la Académie des Inscriptions et Belles-Lettres, que todavía asegura su publicación. En 2018 se editó el volumen XLVIII.

27 John Dowling (ed.), Barcelona, Omega, 1973.

28 Carbonelt, Marta Cristiona (ed.), Juan Pablo Forner, Exequias de la lengua castellana, Madrid, Cátedra, 2003.

29 José Cadalso, Los eruditos a la violeta [...], Madrid, Sancha, 1772.

30 Tomás de Iriarte, Los literatos en cuaresma, en Colección de obras en verso y prosa de D. Tomas de Yriarte, Madrid, Imprenta Real, 1805, t. VII, págs. 9-96 
peración de la filología barroca por otra más moderna, de límites más precisos. Una transición cuya base será la recuperación de la genuina tradición filológica humanista como impugnación de las adherencias barrocas.

\section{La filología española del siglo XVIII}

¿Qué encontramos en la España del siglo XviII? En una apretada síntesis que sin embargo da cuenta de cómo se articulaban las distintas tendencias, podemos hablar de tres ámbitos: los trabajos de paleografía, la línea documentalista y la actividad erudita.

En el campo de la paleografía es preciso mencionar el trabajo de TerrerosBurriel $^{31}$. Se ha hablado también de una supuesta paleografía griega de Juan de Iriarte, pero seguramente se trata de una atribución errónea, porque no se ha hallado documento alguno.

En cuanto a la necesidad de rescatar los documentos del pasado, debe recordarse que Mayans había insistido en la cuestión desde fecha bien temprana. No obstante, no consiguió el apoyo de José Patiño y trató de encauzar el proyecto a través de la Academia Valenciana, pero la publicación de la Censura de historias fabulosas los indispuso con el Consejo de Castilla e hizo fracasar a la Academia. Las ideas de Mayans tuvieron continuidad en los trabajos de Flórez y Burriel. Las divergencias entre don Gregorio y Flórez surgieron pronto a propósito de las tradiciones jacobeas. Por su parte, Burriel fue el encargado de una Comisión de Archivos para localizar documentos que permitieran defender las regalías de la corona ante el papado. No obstante, Ricardo Wall limitó la actividad de la comisión y ordenó la entrega de todos los documentos. Esta decisión debe interpretarse en el contexto del enfrentamiento entre manteístas y colegiales. Debemos recordar también al P. Sarmiento, que había expresado en 1743 en sus Reflexiones Literarias ${ }^{32}$ la necesidad de recuperar los documentos del pasado. A Sarmiento y al P. Ibarreta se les encargó la creación de un corpus diplomaticus, pero Sarmiento era ya muy mayor, y entre los benedictinos de Valladolid surgieron pronto divergencias, de modo que el proyecto no llegó a buen fin. Finalmente, no debe olvidarse que Campomanes impulsó en la Real Academia de la Historia la creación de un Índice general diplomático que luego serviría de modelo para los demás índices.

31 Esteban de Terreros y PAndo, Paleografía española [...], Madrid, Ibarra, 1758.

32 Martín SARMIENTo, Reflexiones literarias para una biblioteca real y para otras bibliotecas públicas, en Antonio Valladares de Sotomayor (ed.), Semanario Erudito, Madrid, Blas Román, 1789, t. XXI, págs. 99-273. 
Por su parte, La actividad erudita se desarrolló en el seno de la Real Biblioteca y la Real Academia de la Historia y en los proyectos de los cronistas.

En el ámbito de la Real Biblioteca es necesario señalar el catálogo de los códices griegos de Juan de Iriarte (Regia biblioteca [...] códices graeci), que es uno de los trabajos de mayor aliento científico de la filología hispana de la época; la biblioteca árabe de Casiri ${ }^{33}$; la reedición de la Bibliotheca de Nicolás Antonio dirigida por Pérez Bayer ${ }^{34}$, quizá uno de los principales proyectos editoriales de la Monarquía; la Biblioteca de traductores de Pellicer ${ }^{35}$, que, también es un hito importante en la historia del cervantismo, surgido precisamente en esta centuria y que es, además, elemento central del hispanismo, sin olvidar, naturalmente, la edición académica del Quijote de $1780^{36}$; la biblioteca rabínica de Rodríguez de Castro $^{37}$ y los trabajos y reediciones de Cerdá y Rico: Luis de Lucena ${ }^{38}$, Matamo$\operatorname{ros}^{39}$, Ginés de Sepúlveda ${ }^{40}$. Finalmente, es preciso recordar que Gregorio Mayans publicó sus Orígenes de la lengua española ${ }^{41}$ cuando estaba al servicio de la Real Biblioteca. La obra es muy importante, entre otras cosas, porque podría considerarse uno de los primeros pasos hacia una historia de la lengua.

No haremos referencia ahora, porque quizá requieren un trabajo específico, a los trabajos de la Real Academia Española (Diccionario, Gramática y Ortografía ${ }^{42}$, que se inscriben en una línea de codificación y unificación lingüística con propósitos utilitarios tal vez de origen racionalista. Como se sabe, alguno de los miembros fundadores de la Academia estaba vinculado a los novatores. No obstante, creo que no debe desdeñarse como precedente la política lingüística de Luis XIV.

33 Miguel CASIRI, Bibliotheca arabico-hispana escurialensis [...], Madrid, Antonio Pérez de Soto, 17601770,2 vols.

34 Nicolás Antonio, Bibliotheca.

35 Juan Antonio Pellicer y SAForcada, Ensayo de una biblioteca de traductores españoles [...], Madrid, Antonio de Sancha, 1778.

36 Real Academia Española, El Ingenioso hidalgo don Quijote de la Mancha. Madrid, Joaquín Ibarra, $1780,2 \mathrm{t}$

37 José Rodríguez de CASTro, Biblioteca española, Madrid, Imprenta Real de la Gaceta, 1781, 2 t.

38 Inscriptiones aliquot collectae ex ipsis Saxis a Ludovico Lucena hispano medico, 1546, ms. copiado por Cerdá en Roma y depositado en la Real Academia de la Historia, E 187.

39 Alphonsi Garsiae Matamori Hispalensis et rhetoris primarii Complutensis Opera omnia [...], Matriti, typis Andreae Ramirez, 1769.

40 Joannis Genesii Sepulvedae cordubensis Opera, cum edita, tum inedita / accurante Regia Historiae Academia [...], Matriti, ex Typographia Regia de la Gazeta, 1780, 4 vols.

${ }^{41}$ Madrid: Juan de Zúñiga, 1737. 2 vols. Como se sabe, Mayans recoge textos de autores anteriores, Juan de Valdés entre otros.

42 Real Academia Española, Diccionario de la lengua castellana [...], Madrid, Francisco del Hierro, 1726-1739, 67 vols.; Gramática de la lengua castellana, Madrid, Ibarra, 1771; Orthographia española, Madrid, Imprenta de la Real Academia, 1741. 
En el seno de la Real Academia de la Historia aún debemos recordar las reediciones de Tomás Antonio Sánchez y Capmany. El primero, dentro de la línea de los medievalistas, editó las obras de Berceo, el Cid, el Libro de Aleixandre y el Libro de buen amor ${ }^{43}$. El segundo es autor del Teatro histórico-crítico de la elocuencia española ${ }^{44}$.

Finalmente, en la línea de los cronistas hay que incluir la Historia del Nuevo Mundo ${ }^{45}$ de Juan Bautista Muñoz.

Las tendencias señaladas coexisten con una filología de influjo racionalista y otra de influjo empirista. La tendencia racionalista se advierte en el deseo de unificación lingüística ${ }^{46}$ y en la aplicación del denominado «método geométrico». El método geométrico se refiere al procedimiento lógico-deductivo derivado del cartesianismo. Transferido al campo filológico, este método podía purificar el fárrago erudito de la polymathia. Se trata de una filología matematizante que podemos hallar, por ejemplo, en los Elementos etimologicos según el método de Euclides ${ }^{47}$ de Sarmiento. Juan Andrés censuró en Origen ${ }^{48}$ la rigidez deductiva del método geométrico en asuntos literarios.

La filología de influencia empirista se advierte sobre todo en el Arte de Benito de San Pedro ${ }^{49}$, y en Origen de toda la literatura de Juan Andrés, al que dedicaremos el siguiente apartado.

Últimamente se ha venido proponiendo la existencia de una «escuela universalista española» (la hipótesis ha sido formulada sobre todo por Pedro Aullón de $\operatorname{Har}^{50}$ ), formada por Juan Andrés, Lorenzo Hervás ${ }^{51}$, Antonio Eximeno y, ya en el ámbito estricto de la historiografía, Francisco Clavijero, autor de la Histo-

43 Tomás Antonio SÁnchez (ed.), Colección de poesías castellanas anteriores al siglo XV, Madrid, Sancha, 1779-1790, 4 t.

44 Antonio Capmany de Montpalau i Surís, Teatro histórico-crítico de la elocuencia española, Madrid, Antonio de Sancha, 1786- 1794, 5 vols.

45 Juan Bautista Muñoz, Historia del Nuevo Mundo, Madrid, Viuda de Ibarra, 1793, t. I.

46 En el uso, pero también en la educación, como se advertirá sobre todo en la segunda mitad de la centuria a partir de las sucesivas leyes que tratan de regular esa cuestión en los diferentes niveles educativos.

47 Edición y estudio de José Luis Pensado, [A Coruña], Fundación Pedro Barrié de la Maza, 1988.

48 Juan ANDrés, Origen, progresos y estado actual de toda la literatura, Jesús García Gabaldón, Santiago Navarro Pastor y Carmen Valcárcel Rivera (eds.), Pedro Aullón de Haro (dir.), 6 vols., Madrid: Verbum, 1997, III, pág. 222. Los seis volúmenes recogen la primera edición española (1784-1806) más la última parte de la edición de Parma.

49 Benito de SAN PEDRo, Arte del romance castellano dispuesta según sus principios generales y el uso de los mejores autores [...], Valencia, Benito Monfort, 1769, 2 tomos en 1 vol.

50 Pedro Aullón de Haro, La Escuela Universalista Española del siglo XVIII, Madrid, Sequitur, 2016.

51 Lorenzo Hervás y PANduro, Catálogo de las lenguas de las naciones conocidas y numeración, división y clases de estas según la diversidad de sus idiomas y dialectos, Madrid, Imprenta de la Administración del Real Arbitrio de Beneficencia, 1800-1805. 6 vols. 
ria antigua de Megico $^{52}$. Creo que no puede dudarse del carácter universalista de la obra de estos autores. Ahora bien, la cuestión importante aquí es saber cuál era la naturaleza de ese universalismo, es decir si este tiene una entidad específica como para hablar de una «escuela española». No sabemos si se trata de un universalismo como el de los enciclopedistas o su origen hay que buscarlo más bien, en una decidida voluntad apologética en el contexto de las críticas de los extranjeros a España, que coincide con una aguda conciencia del declive nacional. Podría hablarse también de una intención apologética en el contexto de la expulsión de los jesuitas (todos esos autores pertenecieron a la Compañía). Para no hablar del universalismo católico. Cualquiera de estas opciones matizaría mucho la existencia de esa supuesta «escuela universalista española» sobre la que albergamos ciertas dudas.

\section{Juan Andrés}

La obra de Juan Andrés supone la culminación de la historia literaria ilustrada y la primera y más sólida propuesta de la historia literaria comparada. Origen, progresos y estado actual de toda la literatura se sitúa en un marco epistemológico comparatista para crear un proyecto empírico basado en la observación. Andrés identifica la literatura con todo lo escrito (los studia humanitatis del Renacimiento). Y, fiel a la herencia humanista, a menudo utiliza los términos filología y gramática como sinónimos (por ejemplo, en la «Prefación» del autor al tomo II de Origen:

La gramática, cultivada con la doctrina y erudición que le dieron los antiguos y los celebrados gramáticos de los felices tiempos del restablecimiento de nuestra literatura, no es materia tan limitada como comúnmente se cree, y comprende la Crítica, la Hermenéutica y toda suerte de estudios filológicos y eruditos ${ }^{53}$.

Andrés concibe la Literatura como una teoría del saber y la gramática como el instrumento epistemológico al servicio de tal teoría ${ }^{54}$. Formula una teoría epistemológica en la que la gramática comprende todas las artes del decir. Parte de la división de la gramática hecha por Quintiliano, que distinguía entre gramática metódica, histórica y crítica. Por ello, divide la gramática en poética,

\footnotetext{
52 [Londres]: Ackermann, 1826.

53 ANDrés, Origen, vol. II, pág. 19.

54 Andrés, Origen, vol. III, págs. 484-486.
} 
retórica y gramática técnica, y esta última, a su vez, en gramatística, etimología y analogía, gramática filosófica y exegética. La concepción de Andrés, que podemos considerar síntesis y cima de su siglo, queda recogida en el cuadro final (FIG.1), donde se exponen las divisiones y subdivisiones formuladas por el jesuita bien de forma explícita bien implícitamente.

\section{El concepto de 'filología'}

Como propusimos al principio, para precisar la idea de filología en España en el siglo XVIII, es necesario abordar la cuestión al menos desde dos puntos de vista: en primer lugar, en relación con los contenidos y tendencias de la actividad filológica durante la centuria, cuestión a la que hemos dedicado las páginas precedentes; en segundo lugar, en relación con el estatuto de la filología respecto de otras disciplinas próximas y respecto del propio movimiento ilustrado español.

Es preciso recordar que, por influjo de la tradición humanista, en el siglo XVIII la «Literatura» se concibe como la totalidad de la cultura escrita. Esta identificación conduce al desarrollo de la erudición histórica o historia erudita. De modo que hasta el siglo XVIII la filología a menudo se confunde con la Historia $^{55}$. Pero en esta centuria comienza el deslinde. Por una parte, ingresan en el campo de la Historia ciertas disciplinas (paleografía, numismática, diplomática) abordadas antes por los filólogos, y otras, como la Arqueología, se independizan como disciplina y se aproximan a la Historia. Por otra parte, asistimos al surgimiento de la historia literaria a partir de los trabajos de los hermanos Mohedano ${ }^{56}$, Velázquez de Velasco ${ }^{57}$, Sarmiento, Pellicer, Tomás Antonio Sánchez, Rodríguez de Castro, Sempere ${ }^{58}$, Trigueros ${ }^{59}$. Y con Juan Andrés hallamos ya plenamente definida la historia literaria comparada.

55 Conviene recordar las disciplinas que conformaban la Historia, lo que nos dará una idea de la amplitud de los estudios filológicos: biografía, cronología, cartografía, hidrografía, literatura de viajes, museística, numismática, epigrafía, diplomática, dactilología.

56 Pedro y Rafael Rodríguez Mohedano, Historia literaria de España desde su primera población hasta nuestros días; origen, progresos, decadencia y restauración de la literatura española, en los tiempos primitivos [...] y de los Reyes Católicos [...], Madrid, Imprenta de Antonio Pérez de Soto, 1766, t. I [-X].

57 José Luis VelázQuez de Velasco [Marqués de Valdeflores], Orígenes de la poesía castellana, Madrid: Imprenta de Francisco Martínez de Aguilar, 1754.

58 Juan Sempere y Guarinos, Ensayo de una biblioteca española de los mejores escritores del reinado de Carlos III, Madrid, Imprenta Real, 1785-1789, 6 vols. Hay edición facsimilar en 3 vols. de la Editorial Gredos, Madrid, 1969.

59 Cándido María Trigueros, Discurso sobre el estudio metódico de la historia literaria [...], Madrid, Benito Cano, [s. a.]. 
Así pues, en el siglo XVII la Historia compite con la Filología en la organización del saber en un proceso que se resuelve en la aparición del enciclopedismo y la historia literaria en la siguiente centuria. Había vencido la Historia, y la filología se replegó sobre sí misma. Entonces la gramática fue gradualmente sustituida como elemento central de la filología por la historia literaria, que evolucionó hacia la historia literaria comparada. La gramática también se haría histórica, después histórico-comparada y más tarde Lingüística.

En este contexto, lo que sucede con la Filología en el siglo XVIII es que se deslinda de la historia, se repliega sobre sí misma y se orienta hacia lo más específicamente literario y lingüístico. Ocurre algo similar a lo señalado por Francisco Rico ${ }^{60}$ para la filología clásica de finales del siglo Xv, cuando el humanismo toca su cota más alta y se cierra sobre sí mismo, pues no puede avanzar ganando terreno a otros saberes, sino a costa de señalarse un marco propio, por lo que debe sacrificar su tentación anexionista. Había proporcionado objetivos y métodos a los demás saberes y aún le quedaba mucho por decir, pero ya no era la vanguardia del conocimiento, su consigna rectora.

En relación con el otro aspecto, la contribución u oposición de la filología al pensamiento ilustrado español, es preciso recordar las tesis de Francisco Sánchez Blanco ${ }^{61}$, que asimila la Ilustración a la renovación científica y excluye a la filología humanista de las fuerzas de progreso. Para él, los humanistas favorecieran y aceptaran sin reservas el absolutismo y lastraron el avance de las ideas reformistas. Pero lo que hemos podido comprobar en nuestro examen es que la tradición humanista fue decisiva en la aparición de la erudición histórica y que esta se transformó en historia crítica a partir de la historiografía de los novatores, que fueron receptivos a las nuevas ideas científicas. Hemos visto también que el humanismo convive en síntesis fecunda con el empirismo en la obra de Juan Andrés, y que un gramático como Benito de San Pedro también abraza el pensamiento empirista. En realidad, el humanismo fue esgrimido como impugnación del escolasticismo. De modo que no creo que debamos excluir a la filología dieciochesca del pensamiento ilustrado, lo que desde luego tampoco nos autoriza a formular la existencia de un «humanismo cristiano» que caracterizaría a nuestra Ilustración, como propone Antonio Mestre ${ }^{62}$. Pero esta ya es otra cuestión.

60 Francisco Rico, El sueño del humanismo (De Petrarca a Erasmo), Madrid, Alianza Universidad, 1993, págs. 73-77 y 87-97.

${ }_{61}$ Francisco Sánchez-Blanco, La mentalidad ilustrada, Madrid, Taurus, 1999, págs. 332-333.

62 Antonio Mestre Sanchís, Humanistas, políticos e ilustrados, Alicante, Universidad de Alicante, 2002. 


\begin{tabular}{|c|c|c|c|}
\hline \multicolumn{4}{|c|}{ GRAMÁTICA TÉCNICA (FIG. 1) } \\
\hline Gramatística & Gramáticas y diccionarios & Gramáticas filosóficas & Exegética \\
\hline $\begin{array}{l}\text { 1. Ortografía } \\
\text { 2. Caligrafía } \\
\text { 3. Paleografía } \\
\text { 4. Arte de } \\
\text { enseñar a los } \\
\text { mudos }\end{array}$ & 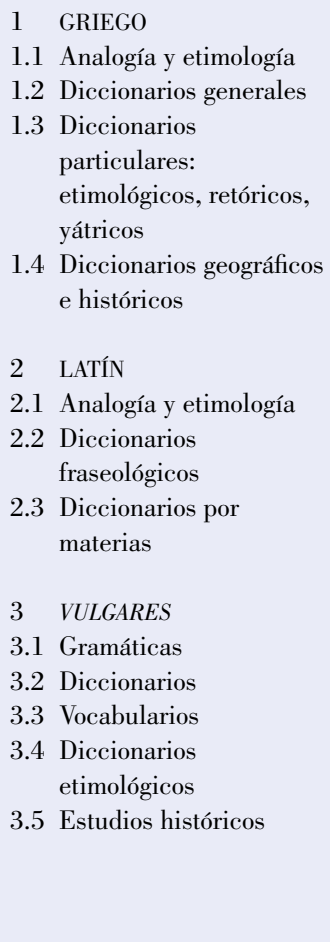 & $\begin{array}{l}\text { 1. Sinonimia } \\
\text { 2. Tropos } \\
\text { 3. Lengua universal } \\
\text { 5. Estudios } \\
\text { etimológicos }\end{array}$ & $\begin{array}{ll}1 & \text { TRADUCCIÓN } \\
1.1 & \text { Antigua: griega, } \\
& \text { latina, árabe } \\
1.1 & \text { Moderna } \\
1.2 & \text { Profana } \\
1.3 & \text { Religiosa: Escrituras, } \\
& \text { patrística }\end{array}$ \\
\hline
\end{tabular}

